\title{
New perspective on Jun glaze corrosion: study on the corrosion of light greenish blue and reddish purple glazes from Juntai Kiln, Yuzhou, Henan, China
}

\author{
Zhimin $\mathrm{Li}^{1}$, Ying Ma ${ }^{1}$, Qinglin Ma2* ${ }^{*}$, Jiachang Chen ${ }^{3}$ and Yan Song ${ }^{4}$
}

\begin{abstract}
The ancient Chinese Jun Porcelain has of typical high fired calcium silicate glaze. After observation of Jun porcelain shards excavated from Juntai Kiln in Yuzhou, Henan Province, China, two pieces with light greenish blue glaze and reddish purple glaze are selected for study as special corrosion samples buried in soil environment. Taking the corrosion of each phase of the overall glaze into consideration, the chemistry compositional and morphological structural features of the earthworm-walking patterns and their surrounding white area (corroded zone) in the glazes are compared and studied with optical microscopy (OM), scanning electron microscopy with energy dispersive X-ray analysis (SEM-EDS), Raman spectroscopy (Raman) and electron microprobe (EPMA): during the firing of Jun Porcelain, the dendritic and columnar crystals coming out of the glaze and mostly in surrounding corroded areas are identified as wollastonite $\left(\mathrm{CaSiO}_{3}\right)$, which provides active sites for localized corrosion. The wollastonite crystalline phases have preferential corrosion initiated by pitting corrosion relative to glassy phase, leaving dendritic or columnar pits and craters to dissolve into calcium ions and silicic acid and losing into the burial environment. Some calcium ions in the surface pits react with dissolved inorganic carbon $(\mathrm{DIC})$ from the soil to form calcium carbonate $\left(\mathrm{CaCO}_{3}\right)$ precipitated on the surface of the glazes. The cracks formed during the cooling process and the interconnected craters caused by crystals dissolution can provide channels to facilitate the progression of the corrosion. This research is of great significance to the study of the corrosion mechanism of ancient porcelain and the conservation of its cultural relics. It has changed the traditional view that porcelain is corrosion-resistant. At the same time, the study of the corrosion process and characteristics of ancient porcelain can provide reference for modern ceramic research and corrosion protection.
\end{abstract}

Keywords: Juntai kiln, Light greenish blue glaze, Reddish purple glaze, Corrosion, Crystals dissolution

\section{Introduction}

Glaze, the glass phase layer covering a porcelain body, is synthesized with natural raw minerals in firing and cooling process. It is essentially the same as glass in material structure and physicochemical properties [1]. Vitreous materials such as coating glaze have a potential chemical resistance. Nevertheless, all vitreous coating can be

\footnotetext{
*Correspondence: qinglinma226@126.com

${ }^{2}$ Institute of Cultural Heritage, Shandong University, Jinan 250100,

Shandong Province, China

Full list of author information is available at the end of the article
}

affected to some extent when coming into contact with water, acid or alkaline liquids [2]. The corrosion of silicate glass in aqueous solutions includes the ion exchange between modifications in glass matrix and hydrogenated species $\left(\mathrm{H}^{+}, \mathrm{H}_{3} \mathrm{O}^{+}, \mathrm{H}_{2} \mathrm{O}\right)$, hydrolysis of ionic-covalent bonds ( $\mathrm{Si}-\mathrm{O}-\mathrm{M}, \mathrm{M}=\mathrm{Si}, \mathrm{Al}$ ), formation of an amorphous silica layer and precipitation of secondary phase crystalline [3-5]. Previous research mainly focuses on the environmental degradation, corrosion mechanisms and long-term behavior of the nuclear waste silicate glass to ensure its safe disposal [6]. Most of the available data
Springer Open

(c) The Author(s) 2020. This article is licensed under a Creative Commons Attribution 4.0 International License, which permits use, sharing, adaptation, distribution and reproduction in any medium or format, as long as you give appropriate credit to the original author(s) and the source, provide a link to the Creative Commons licence, and indicate if changes were made. The images or other third party material in this article are included in the article's Creative Commons licence, unless indicated otherwise in a credit line to the material. If material is not included in the article's Creative Commons licence and your intended use is not permitted by statutory regulation or exceeds the permitted use, you will need to obtain permission directly from the copyright holder. To view a copy of this licence, visit http://creativeco mmons.org/licenses/by/4.0/. The Creative Commons Public Domain Dedication waiver (http://creativecommons.org/publicdomain/ zero/1.0/) applies to the data made available in this article, unless otherwise stated in a credit line to the data. 
are based on short-term simulated corrosion experiments for several days, months or even years to predict the long-term corrosion behavior of glass in specific environments.

Under the action of water, acid, alkali, salt, gas and other mediums, the glaze of ancient glass and ceramics undergoes physical and chemical etching, which is dominated by chemical reactions, in the terrestrial burial environment, immersed in water (ocean, river and lake) or atmospheric environment, resulting in various corrosion phenomena, such as lower gloss, lower smoothness, rough surface, shallower tone, and even more. In some cases, cracks, dense corrosion pits and sediments are formed. Therefore, ancient glaze and ceramic glaze samples exhibit long-term corrosion and weathering behavior in natural preservation environment for hundreds of years or even nearly two thousand years, which can provide helpful information for glaze corrosion studies.

Ancient glass and porcelain corrosion research mainly includes burial-site alteration of lead silicate glaze [7-9], burial-site weathering of lead silicate glass or lead-barium silicate glasses [10], atmospheric or aqueous decay of potassium silicate stained glass window [11-13], geochemical alteration of soda-lime silicate glasses [14], museum condition alteration of soda-rich-silicate and soda-lime silicate glasses [15]. The corrosion of glass and glaze is mostly studied in terms of the glassy phase.

The traditional high-temperature glaze in ancient China belongs to calcium glaze, which can be represented by $\mathrm{CaO}(\mathrm{MgO})-\mathrm{K}_{2} \mathrm{O}\left(\mathrm{Na}_{2} \mathrm{O}\right)-\mathrm{Al}_{2} \mathrm{O}_{3}-\mathrm{SiO}_{2}$ system. However, the ancient Chinese high-temperatured glaze $\left(>1200{ }^{\circ} \mathrm{C}\right.$ ) belongs to calcium glaze or calcium-alkali glaze. Its chemical composition determines that a kind of glaze with complex crystallization, phase separation or phase separation-crystallization structure can be formed during the firing process of calcium glaze [16]. Among these complex glaze-layer porcelains, Jun Porcelain breaks through the previous single-colored glaze such as blue glaze, white glaze and black glaze, and becomes a new variety with bright and changeable colors (such as dramatic bluish opalescent opacity, purple colors and earthworm-walking patterns) [17]. The earthworm-walking patterns are famous and very special phenomenon in Chinese Jun porcelains. The earthworm-walking patterns are formed as follows: when the glaze materials are dried or the kiln is preheated, cracks appear as the water evaporates and the glaze consequently over contracts; as the kiln temperature rises, part of the glaze materials that most easily melt flow to fill the crackles [18]; another view figures out that the glaze materials with large particle size are applied on the body, and cracks appears when the glaze layer is dried, then the other layer of surface glaze with higher $\mathrm{CaO}$ content is also applied on the first glaze, and during firing processing, the surface glaze with lower melting temperature follow to the cracks forming the enamel with different composition [19].

Jun glaze is a glass body with complex phases, such as liquid-liquid phase separation [20, 21], wollastonite, calcareous feldspar and cristobalite crystallization [22], which are formed by complex physical and chemical changes in its firing process. It is both representative and challenging for corrosion research. In this paper, two typical pieces of light greenish blue and reddish purple Jun glaze unearthed from Juntai Kiln site in Yuzhou, Henan Province are explored. The phenomenon and process of long-term corrosion behavior of glaze with complex phases, not limited to glass phase, are discussed from a new perspective.

\section{Materials and methods Materials}

Juntai Kilns in Yuzhou made its debut at the beginning of the Northern Song Dynasty (A.D. 960-1127), culminated in the late Northern Song Dynasty, and continued in operation during Jin Dynasty (A.D. 1115-1234) and early Yuan Dynasty (A.D. 1271-1368). A variety of Jun Porcelain shards of Song Dynasty (960-1279 A.D.), such as flowerpots and flowerpot holders and their broken pieces, was excavated from this site. Two flowerpot shard samples are selected for its unique colors and glaze corrosion. One has white stripes with earthwormwalking patterns scattered on light greenish blue background (Fig. 1a, b), and the other has white stripes with earthworm-walking patterns scattered on reddish purple background (Fig. 1c, d).

\section{Methods}

The two pieces of shards are embedded in epoxy resin and polished with diamond pastes down to $0.1 \mu \mathrm{m}$ to obtain cross-sections.

The samples are examined using a Lecia 4000M optical microscope (OM).

A Renishaw invia Raman spectrometer coupled with $100 \times$ objective lens is employed for identification of crystallized phases in the glaze and the second precipitated crystalline phase on the glaze surface (Raman). The $785 \mathrm{~nm}$ red laser is used and the spectrum is recorded for $20 \times 100 \mathrm{~s}$ with a resolution of $2 \mathrm{~cm}^{-1}$. The spectra of crystals are representative and chosen from at least three different points.

After optical observation and Raman analysis, the surface and cross-sections of the samples are coated with carbon and examined under a TESCAN VEGA3 scanning electron microscope (SEM), with Bruker XFlash $610 \mathrm{M}$ energy dispersive $\mathrm{X}$-ray (EDS) at an accelerating voltage of $20 \mathrm{kv}$. 

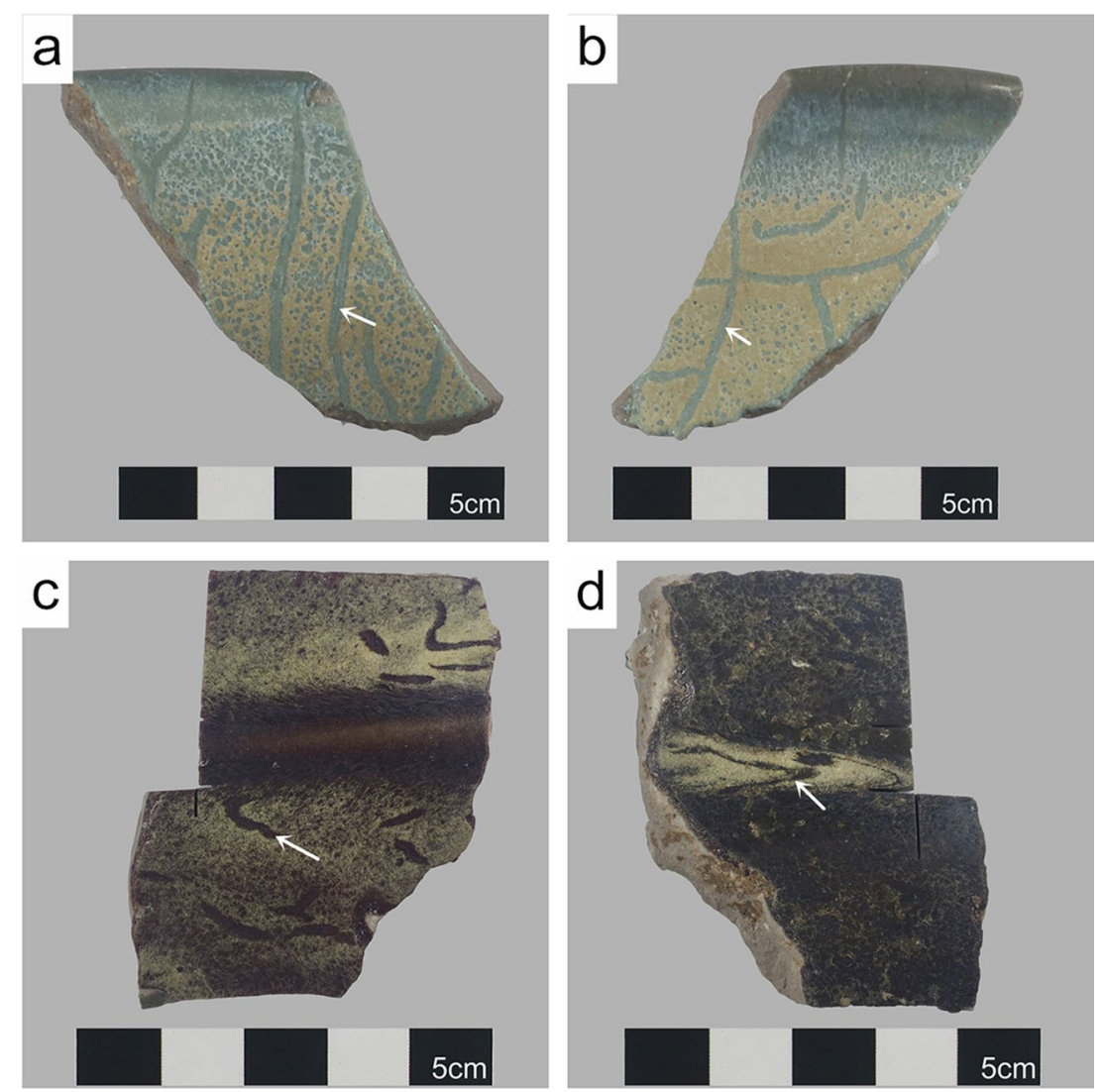

Fig. 1 Jun porcelain flowerpot shards excavated at Juntai Kiln, Yuzhou, Henan: a, b with light greenish blue glaze; c, d with reddish purple glaze; linear patterns resembling earthworm-walking patterns (where the white arrows pointing to)

A Shimadzu EPMA-1720 electron microprobe (EPMA) is used for the chemical analysis of the cross-section of the samples. An electron beam with a diameter of $30 \mu \mathrm{m}$ is used and the probe is run at an accelerating voltage of $20 \mathrm{kv}$ and a beam current of $5 \mathrm{nA}$. The system is calibrated with a natural basalt glass standard.

\section{Results and discussion}

\section{Glaze composition}

The electron microprobe results shown in Table 1 provides the chemical composition of light greenish blue glaze and reddish purple glaze (oxides wt\%). The compositions are quite complex and typical calcium glazes, $\mathrm{SiO}_{2}, \mathrm{Al}_{2} \mathrm{O}_{3}, \mathrm{CaO}$ and $\mathrm{K}_{2} \mathrm{O}$ being the four major constituents.

\section{Corrosion of light greenish blue glaze}

The gloss and smoothness of the light greenish blue glaze decrease due to corrosion. The enamel around the earthworm-walking patterns is corroded seriously. The moon white rubbery color of the stripes turns to yellowish and the surface is rough.

In this study, the surface and cross-section of the light greenish blue glaze are examined with OM, SEM-EDS

Table 1 Chemical composition (wt\%) of the glazes and bodies analyzed by EPMA

\begin{tabular}{|c|c|c|c|c|c|c|c|c|c|c|c|c|c|c|}
\hline Samples & Area & $\mathrm{Na}_{2} \mathrm{O}$ & $\mathrm{MgO}$ & $\mathrm{Al}_{2} \mathrm{O}_{3}$ & $\mathrm{SiO}_{2}$ & $\mathrm{P}_{2} \mathrm{O}_{5}$ & $\mathrm{~K}_{2} \mathrm{O}$ & $\mathrm{CaO}$ & $\mathrm{TiO}_{2}$ & $\mathrm{MnO}$ & $\mathrm{Fe}_{2} \mathrm{O}_{3}$ & $\mathrm{CoO}$ & $\mathrm{CuO}$ & $\mathrm{ZnO}$ \\
\hline \multirow[t]{2}{*}{ Light greenish blue } & Glaze & 0.57 & 1.17 & 10.71 & 69.05 & 0.62 & 4.28 & 10.21 & 0.29 & 0.06 & 2.94 & 0.05 & 0.02 & 0.03 \\
\hline & Body & 0.27 & 0.78 & 31.84 & 59.39 & 0.10 & 2.74 & 0.63 & 1.10 & 0.05 & 3.05 & 0.01 & 0.01 & 0.02 \\
\hline \multirow[t]{2}{*}{ Reddish purple } & Glaze & 0.37 & 1.03 & 10.51 & 68.38 & 0.41 & 3.94 & 12.22 & 0.33 & 0.06 & 2.47 & - & 0.25 & 0.02 \\
\hline & Body & 0.21 & 0.75 & 27.98 & 63.69 & 0.06 & 2.77 & 0.72 & 0.85 & 0.06 & 2.85 & - & 0.05 & - \\
\hline
\end{tabular}


and Raman to compare the compositional and chemical characterization of earthworm-walking patterns area with the result of corroded area.

\section{Surface examinations}

Figure 2 shows OM and SEM-BSE images of the surface of the light greenish blue glaze. No signs of corrosion in the earthworm-walking patterns area can be seen (Fig. 2a), while dendritic pits or holes in corroded areas can be seen, making the glass phase change to yellow
(Fig. 2b). Figure 2c indicates that the glaze in earthworm-walking patterns area is very variable: the grayish white round area (where the black arrow pointing to) of the glaze, appearing opaque, is much smoother than its surrounding area, and residual quartz grains and crystals can be seen at its core. SEM-EDS analysis shows that this area has higher $\mathrm{CaO}$ and $\mathrm{Fe}_{2} \mathrm{O}_{3}$ content than its surroundings (Table 2). Figure $2 \mathrm{~d}$ shows dendritic pits and holes on the surface of corroded areas.
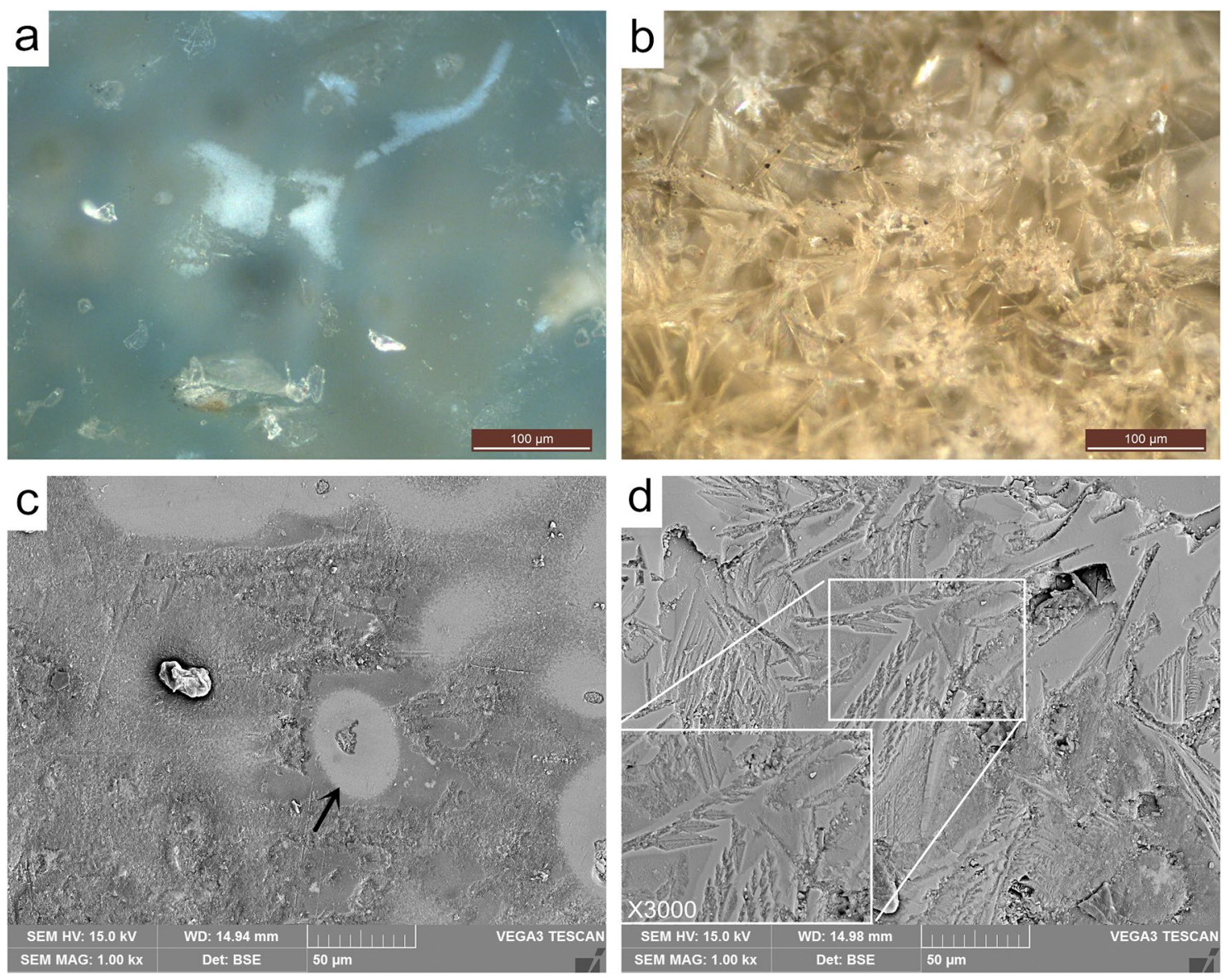

Fig. 2 OM photos and SEM-BSE images of the light greenish blue glaze surface: $\mathbf{a}, \mathbf{c}$ the linear patterns resembling earthworm-walking patterns, i.e. the area without corrosion; c grayish white area (where the black arrow pointing to) with Ca-content and Fe-content higher than its surrounding area; $\mathbf{b}, \mathbf{d}$ corrosion area with dendritic pits and holes

Table 2 Chemical composition (wt\%) of the earthworm-walking patterns area (Fig. $2 c$ ) of light greenish blue glaze surface

\begin{tabular}{llllllll}
\hline Position & $\mathrm{Na}_{\mathbf{2}} \mathbf{O}$ & $\mathbf{M g O}$ & $\mathbf{A l}_{\mathbf{2}} \mathbf{O}_{\mathbf{3}}$ & $\mathbf{S i O}_{\mathbf{2}}$ & $\mathbf{K}_{\mathbf{2}} \mathbf{O}$ & $\mathrm{CaO}$ & $\mathrm{Fe}_{\mathbf{2}} \mathrm{O}_{\mathbf{3}}$ \\
\hline Round area & 0.4 & 0.4 & 7.3 & 67.7 & 5.7 & 14.5 & 3.9 \\
Surrounding & 1.0 & 0.4 & 8.9 & 76.3 & 4.8 & 6.2 & 2.3 \\
\hline
\end{tabular}




\section{Cross-section examinations}

To complete the study, the cross-section of the greenish blue glaze (Fig. 3) is also examined with OM and SEMEDS and the chemical composition of different areas is shown in Table 3.

Figure 3a, b indicates the morphology of the cross-section of the whole glaze. In Fig. 3a, the earthworm-walking patterns area is marked as $\square \mathrm{C}$ and the corroded areas are marked as $\square \mathrm{E}$ and $\square$ J.
Figure 3c, d shows the morphologic characterization of earthworm-walking patterns area, corresponding to Fig. 3a $\square$ C. In this area, the glassy phase is not corroded and can be related with better chemical resistance, containing blue-transparent areas and opaque areas.

The crystals formed during the firing are severely corroded as seen at the black dendritic pits and holes (where the black arrow pointing to) in Fig. $3 e$ and $3 f$, and the areas containing crystals without corrosion present the

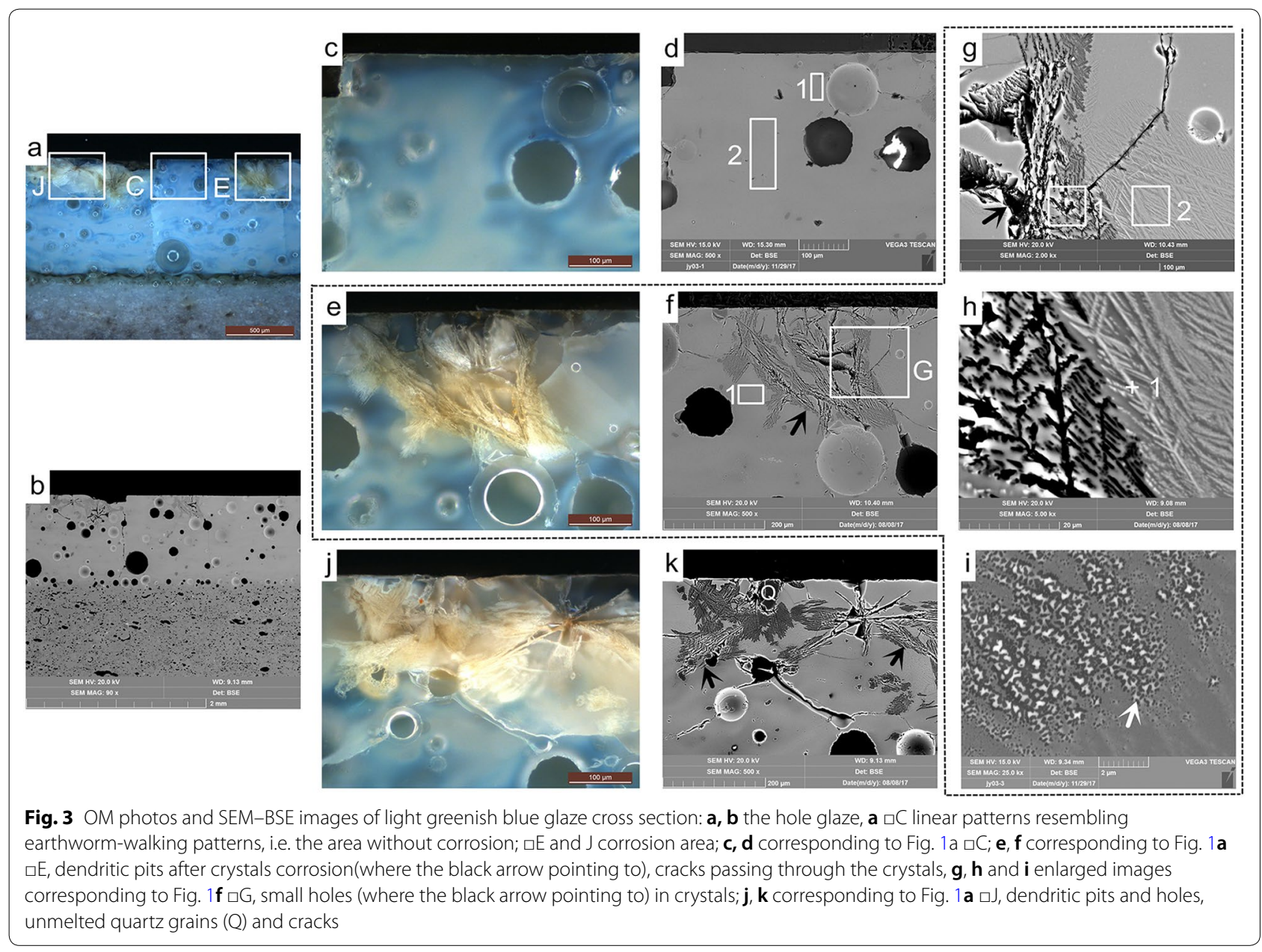

Table 3 Chemical composition (wt. \%) of the light greenish blue glaze cross section

\begin{tabular}{llllllll}
\hline Position & $\mathbf{N a}_{\mathbf{2}} \mathbf{O}$ & $\mathbf{M g O}$ & $\mathbf{A l}_{\mathbf{2}} \mathbf{O}_{\mathbf{3}}$ & $\mathbf{S i O}_{\mathbf{2}}$ & $\mathbf{K}_{\mathbf{2}} \mathbf{O}$ & $\mathbf{C a O}$ & $\mathbf{F e}_{\mathbf{2}} \mathbf{O}_{\mathbf{3}}$ \\
\hline Figure 3d EDS1 & 0.4 & 1.2 & 10.9 & 68.2 & 4.8 & 11.9 & 2.6 \\
Figure 3d EDS2 & 0.7 & 0.9 & 9.9 & 67.6 & 3.6 & 14.1 & 3.2 \\
Figure 3f EDS1 & 0.4 & 1.1 & 10.8 & 71.5 & 3.8 & 10.8 & 1.6 \\
Figure 3g EDS1 & 0.9 & 1.1 & 13.6 & 66.1 & 6.1 & 5.4 & 0.1 \\
Figure 3g EDS2 & 0.2 & 0.8 & 9.5 & 59.1 & 5.1 & 22.9 & 2.4 \\
Figure 3h EDS1 & 0.3 & 1.3 & 7.0 & 57.1 & 2.6 & 30.2 & 1.5 \\
\hline
\end{tabular}


white color and opaque effect like jade. Figure $3 g$, h are enlarged pictures corresponding to the Fig. $3 f \square G$, further conforming these black pits and holes (where the black arrow pointing to) are caused by crystals dissolution because the shape of the pits and holes is consistent with crystal morphology, and the crystals are also corroded preferentially along the cracks. The corrosion micro-pits (where the white arrow pointing to) observed in the dendritic crystals in Fig. $3 \mathrm{i}$ show the evidence that the pitting corrosion is mostly caused by incongruent dissolution in the crystals.

These pits and holes are more clearly seen along the cracks in Fig. 3k, which corresponds to the area in Fig. 3j with opaque yellow color. The cracks mainly propagate in various directions from the glaze surface to the inner glaze taking larger residual quartz as the core $\left(\square \mathrm{Q}, \mathrm{SiO}_{2}\right.$ $100.0 \mathrm{wt} \%)$. These cracks are formed during the firing process and easily shown in the crystals, even as larger grains. During the cooling process, constraints occur at the interface due to difference thermal expansion, and when the mechanical stress reaches a critical value, cracks form and release part of the constraints. These residual constraints, crystals and bubbles are heterogeneities that cause the nucleation of cracks. Depending on the distribution of nucleation sites and on the mechanical stress remaining in the system, cracks can propagate in various directions from the glaze-body interface to the glaze surface [23, 24].

The microstructure of Jun glaze is very complex. It includes amorphous glassy phase, liquid-liquid phase separation in glass matrix, crystalline phase and gas phase, leading to inhomogeneous chemical composition of the glaze layer. In sum, for the earthworm-walking patterns area, when compared with blue-transparent areas, opaque areas have higher $\mathrm{CaO}$ content (each color area is analyzed with SEM-EDS at three different places, e.g. Fig. 3d EDS1: $\mathrm{CaO} 11.9$ wt\%, EDS2: $\mathrm{CaO} 14.1$ wt\%). Consistent with the contributing factors for earthwormwalking patterns $[18,19]$, the content of $\mathrm{CaO}$ as flux and $\mathrm{Fe}_{2} \mathrm{O}_{3}$ as the colorants of the patterns are higher than those of the glaze at corroded areas (comparing blue area of this pattern with blue area in corroded areas, e.g. Figure 3d EDS1: $\mathrm{CaO} 11.9 \mathrm{wt} \%, \mathrm{Fe}_{2} \mathrm{O}_{3} 2.6 \mathrm{wt} \%$ with Fig. 3f EDS1: $\left.\mathrm{CaO} 10.8 \mathrm{wt} \%, \mathrm{Fe}_{2} \mathrm{O}_{3} 1.6 \mathrm{wt} \%\right)$. As the contents of $\mathrm{CaO}$ and $\mathrm{Fe}_{2} \mathrm{O}_{3}$ increase, the glaze viscosity and surface roughness decrease, resulting in a smooth surface and better chemical durability of this area. For corroded areas, several dendritic crystals without corrosion appear. These crystals have $\mathrm{CaO}$ and $\mathrm{SiO}_{2}$ as their main constituents (three different points are analyzed and their composition is similar, e.g. Fig. 3h EDS1), and Raman spectra (Fig. 4) indicate these crystals are wollastonite, i.e. $\mathrm{CaSiO}_{3}$. Comparing the element composition

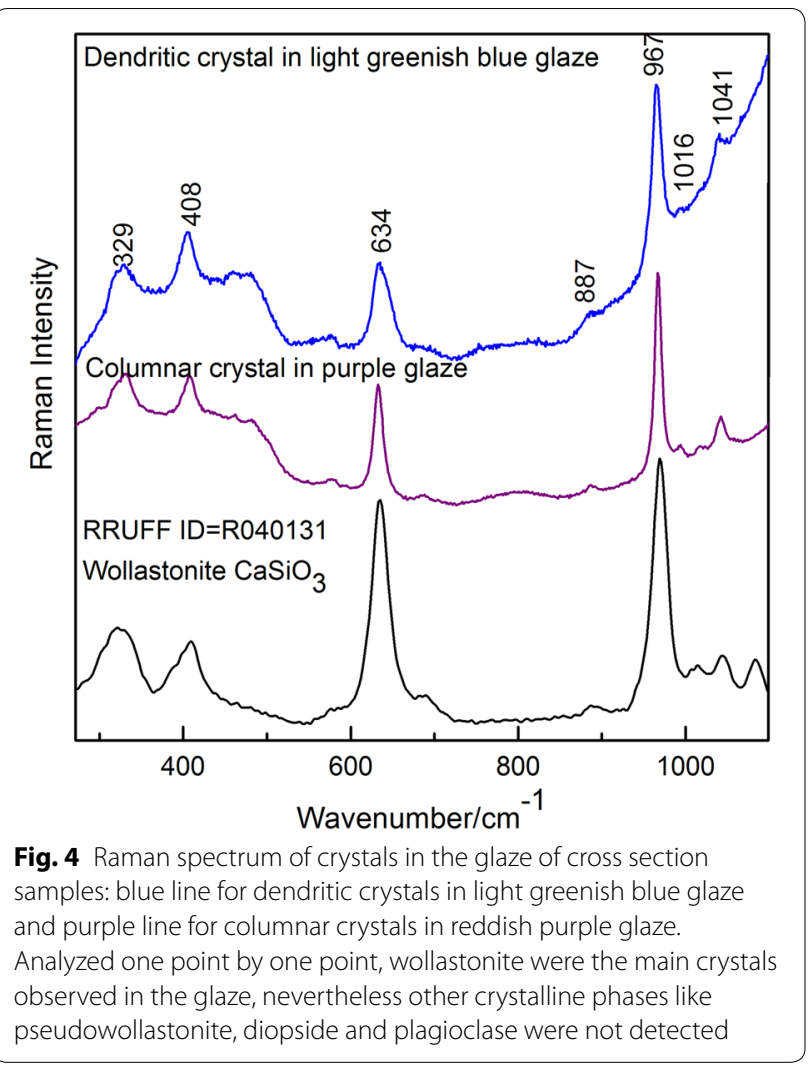

of wollastonite corroded pits area (Fig. 3g EDS1) with uncorroded wollastonite area (Fig. 3g EDS2), the $\mathrm{CaO}$ is depleted, suggesting the dissolution of wollastonite crystals.

\section{Corrosion of reddish purple glaze}

Similar to the light greenish blue glaze, the reddish purple glaze sample is also examined.

\section{Surface examination}

Slight signs of corrosion in the earthworm-walking patterns area can be seen as columnar pits only at the glaze surface in Fig. 5a, b. Figure 5c show the white stripes and tiny craters scatter in the glass matrix in the corrosion area. Obviously in Fig. 5d, both columnar pits and craters can be seen. In this area, columnar pits are denser than those in the earthworm-walking patterns area and craters spread from surface to inner glaze (where white arrows pointing to). The SEM-EDS analysis indicates higher flux and colorant contents of this area than its surroundings (the corrosion area), consistent with the result from the light greenish blue glaze. Some secondary phases rich in calcium in terms of precipitated crystals (where the black arrow pointing to) form in the pits and craters as seen in Fig. 5e, f. Further Raman analysis indicates that these 

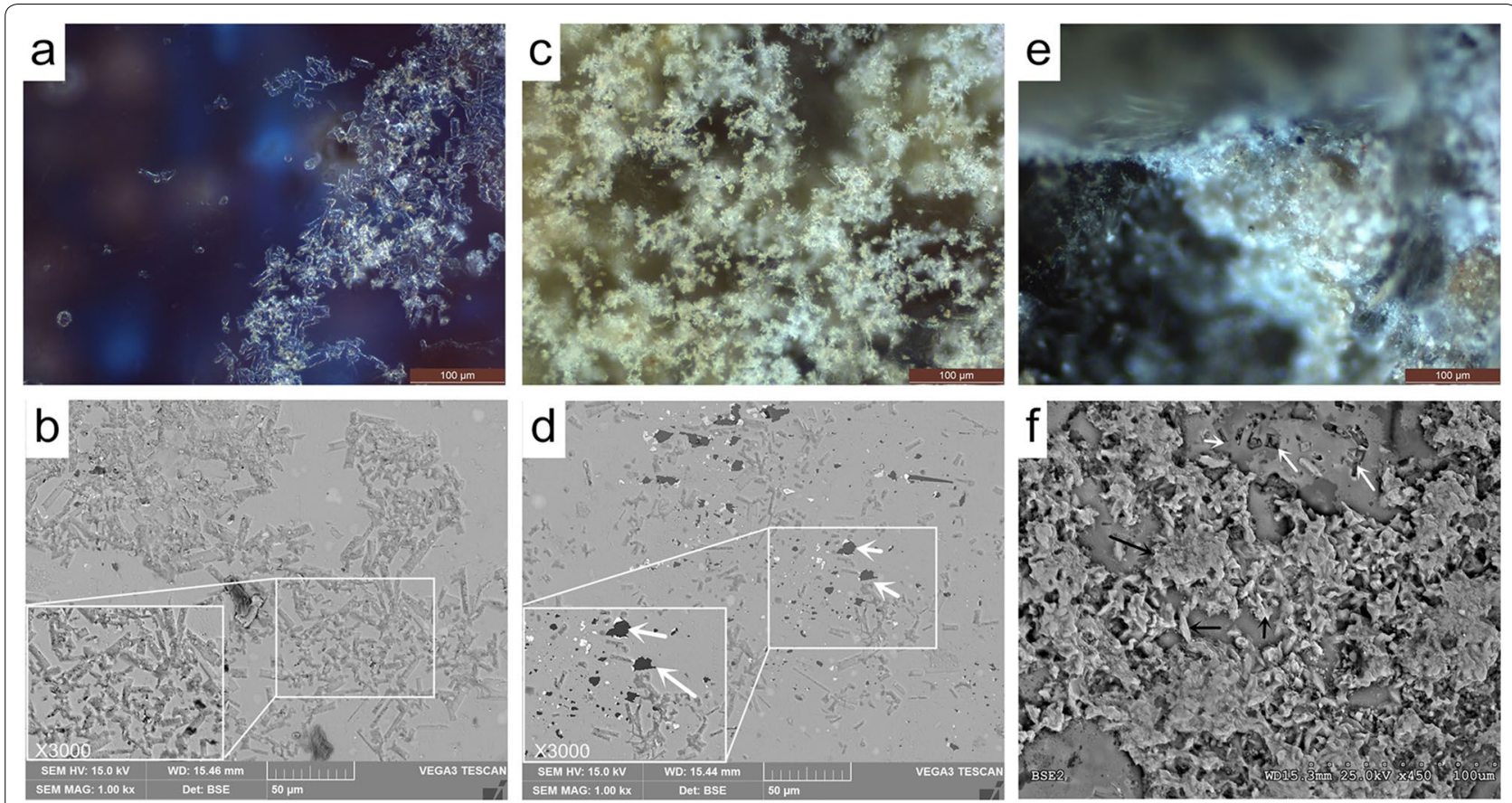

Fig. 5 OM photos and SEM-BSE images of the reddish purple glaze surface: $\mathbf{a}, \mathbf{b}$ linear patterns resembling earthworm-walking patterns, i.e. the area with crystals corrosion only at the glaze surface; $\mathbf{c}, \mathbf{d}$ the corrosion area, columnar pits and craters spreading to inner glaze (where white arrows pointing to), e, f secondary phases precipitated crystals in pits and craters (black arrow), pits without crystals (where white arrows pointing to)

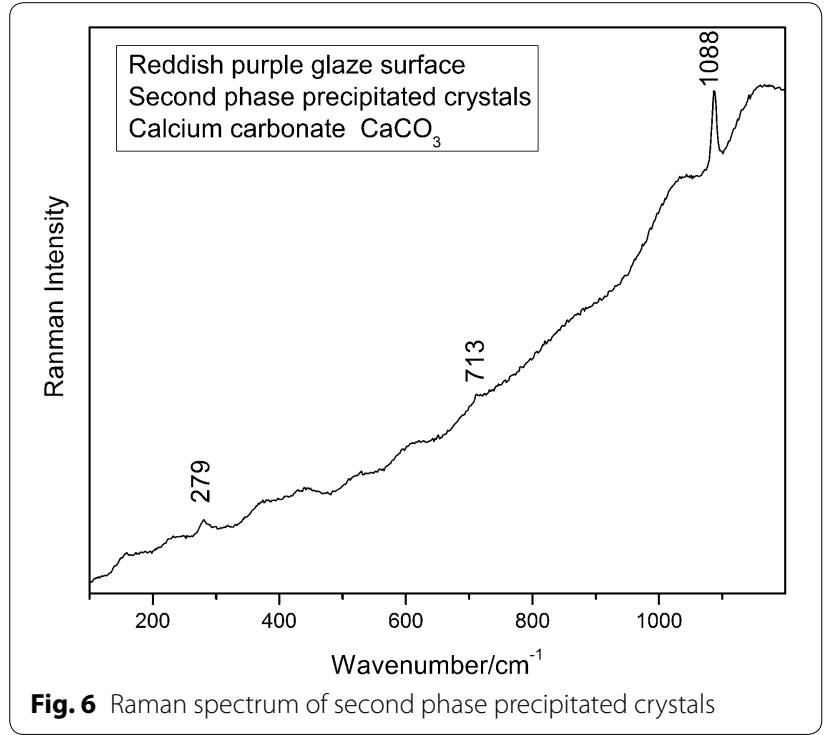

white crystalline phases are calcium carbonate, $\mathrm{CaCO}_{3}$ (Fig. 6).

\section{Cross-section examinations}

The cross-section of the reddish purple glaze (Fig. 7) is also analyzed with OM and SEM-EDS and the chemical composition of different areas is shown in Table 4.
Figure $7 \mathrm{a}, \mathrm{b}$ reveals the morphology of the whole reddish purple glaze cross-section. In Fig. $7 \mathrm{a}$, the earthworm-walking patterns area is marked as area $\square \mathrm{C}$ and corroded area marked as area $\square \mathrm{E}$.

Figure $7 \mathrm{c}$ and $\mathrm{d}$ are enlarged images of the earthwormwalking patterns area, which shows the purple-transparent glassy phase layer at the inner surface and tiny columnar crystals in vitreous matrix under the transparent layer. The areas (Fig. 7d EDS2) containing tiny crystals also show opaque effect and are not corroded because they are covered by glassy phase. These crystals are also confirmed to be wollastonite through Raman analysis as shown in Fig. 4. According to the result of the surface examination, the wollastonite crystals are corroded only at the glaze-surface in this area since the propagation path of crystals stops before reaching the inner glaze.

Figure $7 \mathrm{e}, \mathrm{f}$ indicates that tiny columnar wollastonite crystals connect to each other and propagate from the glaze surface to inner glaze. The interconnected pits and craters formed by these crystals are severely corroded, which can be seen where white arrows are pointing to in Fig. 7f. In addition, these interconnected pits and craters as transfer channels allowing the medium to reach the inner glaze enhance the development of corrosion. When comparing the element composition of wollastonite corroded pits area (Fig. 7f EDS1) with the uncorroded 

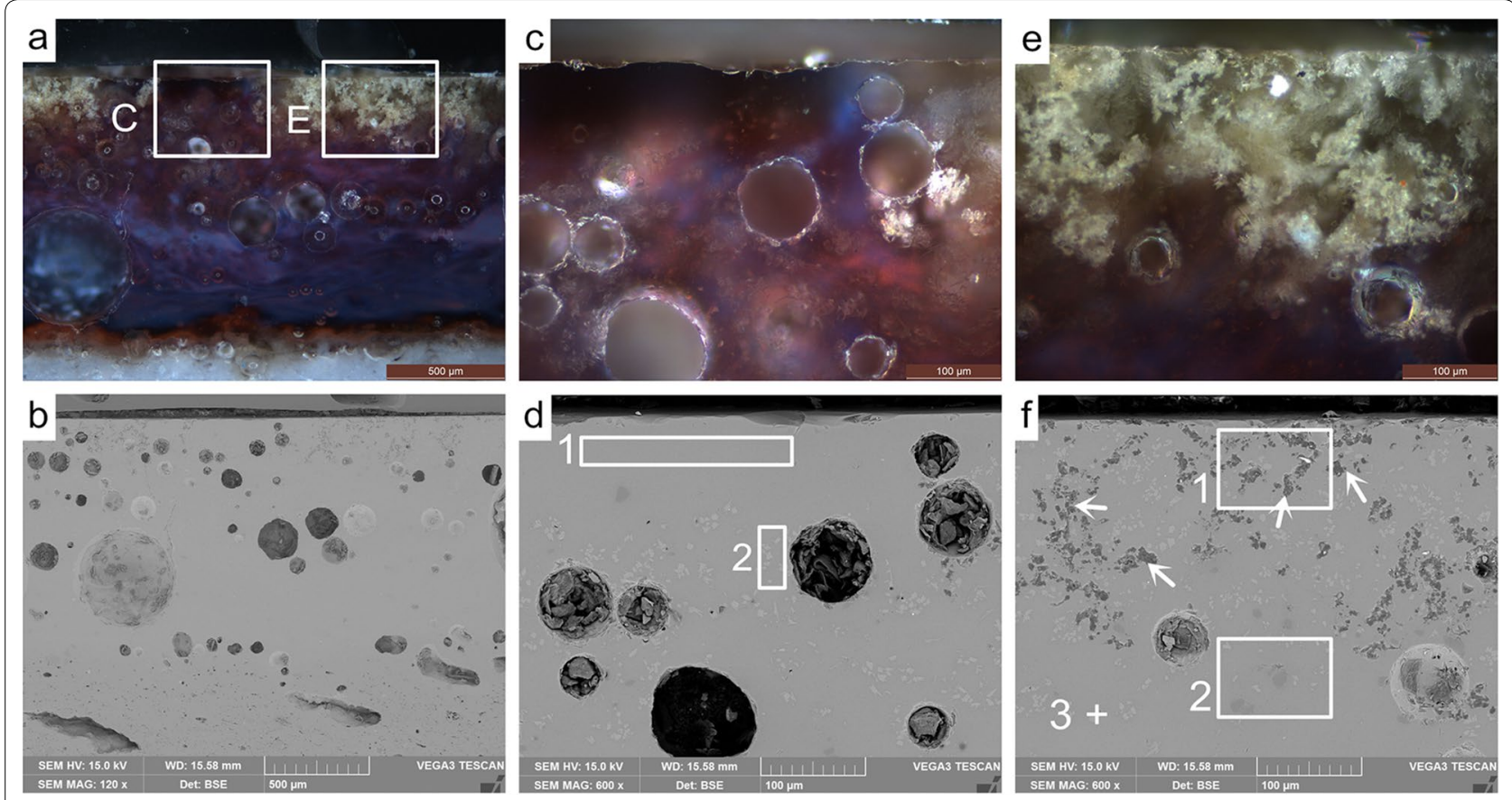

Fig. 7 OM photos and SEM-BSE images of the reddish purple glaze cross section: $\mathbf{a}$, $\mathbf{b}$ the hole glaze, $\mathbf{a} \square \mathrm{C}$ linear patterns resembling earthworm-walking patterns, i.e. the area without corrosion; $\square$ E corrosion area; $\mathbf{c}, \mathbf{d}$ corresponding to Fig. $1 \mathbf{a} \square C ; \mathbf{e}, \mathbf{f}$ corresponding to Fig. 1 $\mathbf{a} \square E$, columnar pits and craters after crystals corrosion, large interconnecting craters from the surface to inner glaze (where white arrows pointing to)

Table 4 Chemical composition (wt.\%) of the reddish purple glaze cross section

\begin{tabular}{lllccccc}
\hline Position & $\mathbf{N a}_{\mathbf{2}} \mathbf{O}$ & $\mathbf{M g O}$ & $\mathbf{A l}_{\mathbf{2}} \mathbf{O}_{\mathbf{3}}$ & $\mathbf{S i O}_{\mathbf{2}}$ & $\mathbf{K}_{\mathbf{2}} \mathbf{O}$ & $\mathbf{C a O}$ & $\mathbf{F e}_{\mathbf{2}} \mathbf{O}_{\mathbf{3}}$ \\
\hline Figure 7d EDS1 & 0.3 & 0.7 & 9.8 & 71.9 & 5.3 & 10.3 & 1.6 \\
Figure 7d EDS2 & 0.2 & 0.7 & 8.6 & 67.8 & 6.0 & 15.1 & 1.5 \\
Figure 7f EDS1 & 0.4 & 0.8 & 12.0 & 69.1 & 5.3 & 10.5 & 1.9 \\
Figure 7f EDS2 & 0.5 & 0.6 & 9.3 & 73.2 & 4.5 & 10.6 & 1.3 \\
Figure 7f EDS3 & 0.1 & 1.2 & - & 47.0 & - & 50.8 & - \\
\hline
\end{tabular}

wollastonite area (Fig. 7d EDS2), It indicates that the $\mathrm{CaO}$ content of the latter also decreases.

\section{Glaze characterization}

The ancient Jun Porcelain is celebrated for its variety of glaze colors, such as rose purple, begonia red, reddish purple, grape purple, greenish blue, moon white, sky blue, light yellow, soybean green, which can be grouped into two types of blue/green and purple/red colorants [25] (Fig. 1). The blue/green colors are related to both iron oxide colorant and the blue-opaque caused by the microstructure change of liquid-liquid phase separation [26]. The purple/red colors are the result of the presence of small copper metal nanoparticles or even copper sulfide particles [27]. Moreover, the presence of unmelted quartz, micro-crystallites, bubbles and cracks is also responsible for the opalescence.
Jun glaze, composed of crystals, bubbles, phase separation, is inhomogeneous as a result of the difference in raw materials and manufacture technology. Meanwhile, defects such as cracks, pinholes, blemishes, blisters and solid grains appear at its surface. These defects can easily induce aqueous medium retention and provide both surface area for sustained reactions and active sites for localized corrosion [28].

In the light greenish blue glaze and reddish purple glaze corrosion areas, dendritic and columnar wollastonite crystalline particles form at their surface, appearing to become active corrosion sites and tend to produce selective corrosion for the overall glaze. The cracks penetrating from the surface to inner light greenish blue glaze provide channels for the corrosive medium to immerse into internal glaze and react with the crystals. Corrosion occurs at the crack lines. Nevertheless, the corrosion 
channels in reddish purple glaze form as a result of interconnected columnar pits or craters caused by localized corrosion of wollastonite crystals. The corrosion channels force the corrosion front to move into internal glaze from the surface.

These corrosion pits or craters contribute to the appearance of Jun glaze seen today, with its opaque effect even enhanced.

\section{Glaze corrosion behavior and process}

The corrosion of Jun glaze occurs as a result of environmental interaction during its burial at ambient temperature. A possible explanation for the findings previously discussed about surface and cross-section examinations is schematically presented in Fig. 8. The behavior and process of glaze corrosion is explained as follows:

\section{Step 1. Crystal dissolution}

These Jun Porcelain shards are found near the surface, about 0.4-0.8 $\mathrm{m}$ down, in grayish brown and loose soils in Yuzhou, Henan Province [25].

The structure of wollastonite consists of infinite chains composed of a pair of corner-sharing tetrahedra alternating with a single tetrahedron with one edge parallel to the chain direction; layers of $\mathrm{Ca}$ atoms in octahedral coordination alternate with layers of $\mathrm{Si}$ atoms [29, 30]. It is generally known that wollastonite dissolves incongruently with the faster release of $\mathrm{Ca}$ relative to $\mathrm{Si}$ in an acid solution.
The $\mathrm{Ca}-\mathrm{H}$ exchanges reactions and forms altered layers enriched in silica [30,31]. The wollastonite crystals in the glaze dissolve in acidic and neutral aqueous solutions through corrosion reactions at interfaces, crystal planes and boundaries [32]. The tiny columnar wollastonite crystals at the glaze surface dissolve easily in acidic to slightly alkaline solutions. The dendritic wollastonite crystals dissolve only in acidic solutions in 4 days, showing a better chemical resistance when they contain some alumina [33]. Wollastonite-type crystals in the glaze surfaces were attacked in a slightly alkaline aqueous solutions containing typical cleaning agents [34]. As for the overall Jun glaze, wollastonite crystals have a poor chemical resistance for aqueous solutions, resulting in the preferential corrosion of wollastonite crystals relative to the glassy phase.

Water molecules in soil can be absorbed from soil moisture and form a water film on the glaze surface, even more easily on glaze defects. The exchange between $\mathrm{Ca}^{2+}$ and $\mathrm{H}^{+}$ occurs at wollastonite surface in solutions which releases $\mathrm{Ca}$ and $\mathrm{Si}$ (Eq. 1) and (Eq. 2):

$$
\begin{aligned}
& \mathrm{CaSiO}_{3}+2 \mathrm{H}^{+} \rightarrow \mathrm{Ca}^{2+}+\mathrm{SiO}_{2} \cdot \mathrm{H}_{2} \mathrm{O} \\
& \mathrm{H}_{2} \mathrm{SiO}_{3}+\mathrm{H}_{2} \mathrm{O} \rightarrow \mathrm{H}_{4} \mathrm{SiO}_{4}
\end{aligned}
$$

The release rate of wollastonite dissolving with calcium is higher than the silicon one until $\mathrm{Ca}$ is depleted,

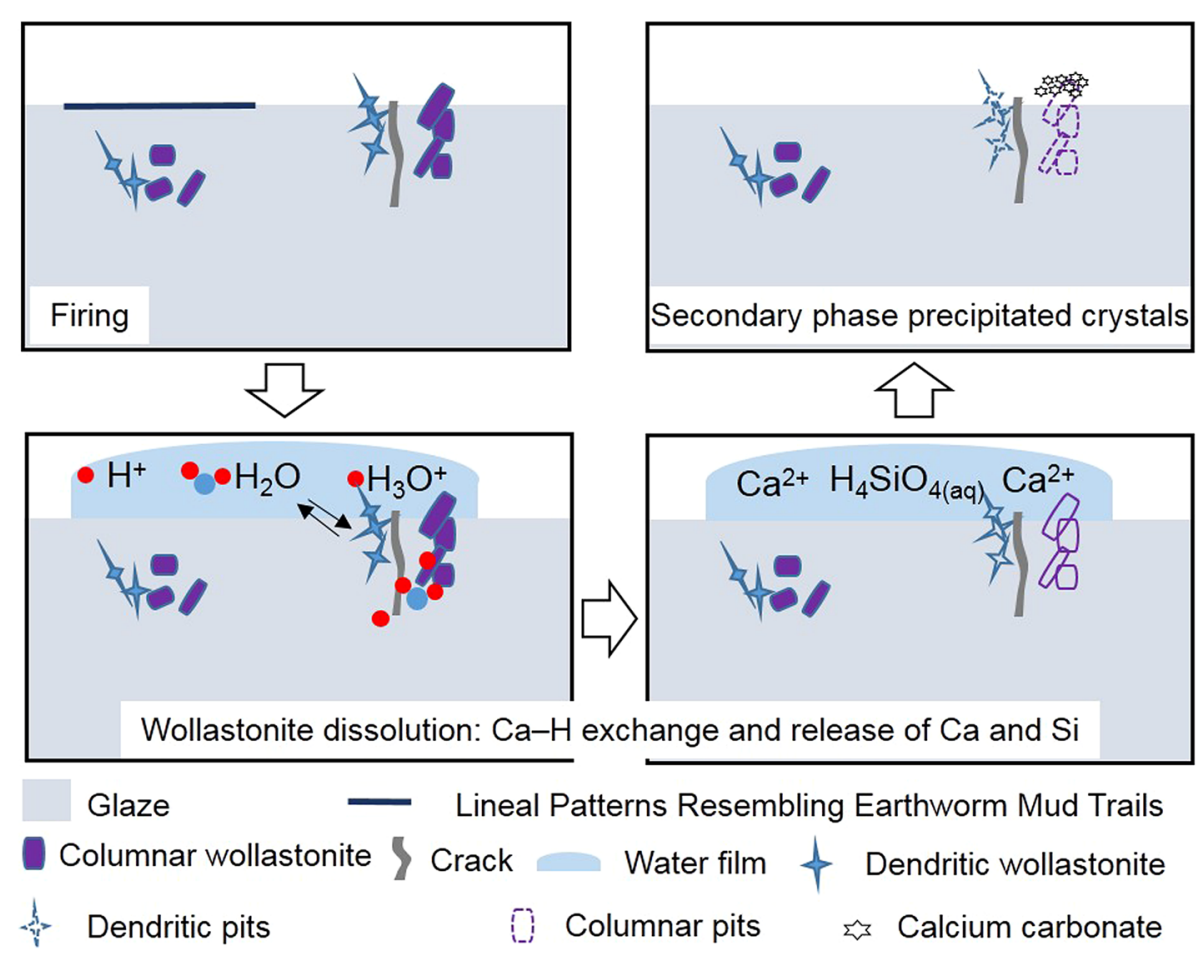

Fig. 8 Schematic illustration of the process of Jun glaze corrosion 
and preferential (incongruent) Ca-leaching relative to $\mathrm{Si}$ can be confirmed by the perseverance of etch micro-pits in the dendritic wollastonite (Fig. 3i) and the decrease of Ca content and Wollastonite dissolution creates pits and craters in the glaze.

\section{Step 2. Secondary phase precipitation}

Water interacting with $\mathrm{CO}_{2}$ (Eqs. 3, 4) forms the dissolved inorganic carbon $\left(\mathrm{DIC}=\left[\mathrm{CO}_{2}(\mathrm{aq})\right]+\left[\mathrm{HCO}_{3}^{-}\right]\right.$ $\left.+\left[\mathrm{CO}_{3}^{2-}\right]\right)[35]$ :

$$
\begin{aligned}
& \mathrm{CO}_{2}(\mathrm{~g}) \leftrightarrow \mathrm{CO}_{2}(\mathrm{aq}) \\
& \mathrm{CO}_{2}(\mathrm{aq})+\mathrm{H}_{2} \mathrm{O} \leftrightarrow \mathrm{H}_{2} \mathrm{CO}_{3} \\
& \leftrightarrow \mathrm{HCO}_{3}^{-}+\mathrm{H}^{+} \\
& \leftrightarrow \mathrm{CO}_{3}^{2-}+2 \mathrm{H}^{+} \\
& \mathrm{Ca}^{2+}+\mathrm{CO}_{3}^{2-} \rightarrow \mathrm{CaCO}_{3} \downarrow+\mathrm{H}_{2} \mathrm{O}
\end{aligned}
$$

With the reaction (1) and (2), $\mathrm{H}^{+}$ions is consumed whereas $\mathrm{Ca}^{2+}$ ions increases. Calcium ions react with water and $\mathrm{CO}_{2}$ or $\mathrm{CO}_{3}{ }^{2-}$ (Eq. 5) at the solid/liquid interface to form calcium carbonate enriched in the pits and craters. On the basis of the carbonation wollastonite equation, i.e. $\mathrm{CaSiO}_{3}+\mathrm{CO}_{2} \rightarrow \mathrm{CaCO}_{3}+\mathrm{SiO}_{2}$, the standard Gibbs free energy of the reaction is $-134.00 \mathrm{~kJ} /$ mol, given that $\Delta \mathrm{G}<0$, the crystallization reaction can occur spontaneously at the standard state [36]. In the summary, the carbonation of wollastonite crystals in the Jun glaze easily occurs under the influence of environment inorganic carbon (DIC) at the burial atmosphere.

\section{Conclusion}

In this research, two typical samples of light greenish blue and reddish purple Jun Porcelain glazes from an over 1000-year-old kiln site in Yuzhou, Henan Province are selected to study the corrosion phenomenon and process of Jun glaze in burial site.

The results are summarized as below:

1. During the firing of Jun Porcelain, dendritic and columnar crystals separated from the light greenish blue and reddish purple glaze are identified to be wollastonite $\left(\mathrm{CaSiO}_{3}\right)$. These crystals coming out of the surface appear to form inhomogeneous area and provide active sites for localized corrosions.

2. For the overall Jun glaze, the corrosion is different and selective corrosions tend to occur. The wollastonite crystalline phases have preferential corrosion relative to glassy phase in burial sites, leaving dendritic or columnar pits and craters in the glaze, whereas dendritic wollastonite crystals dissolution is initiated by pitting corrosion.
3. The wollastonite crystals in Jun glaze dissolve into calcium ions and silicic acid, losing into the burial environment. Some calcium ions in the surface pits react with dissolved inorganic carbon (DIC) from the soil to precipitate crystalline calcium carbonate second phase $\mathrm{CaCO}_{3}$.

4. Cracks form during Jun glaze cooling process and interconnected craters caused by crystals dissolution would provide channels for the transport of aqueous medium toward the deeper glaze to facilitate the progression of the corrosion. In addition, the corrosion enlarges the cracks, pits and craters and partly enhances the opaque effect of Jun glaze observed today.

\section{Acknowledgements}

The authors wish to express their great gratitude to the Researchers Naisheng $\mathrm{Li}$ at the Chinese Academy of Cultural Heritage, Professor Yanxiang Li and Dr. Hongjiao Ma at the University of Science and Technology Beijing for their kind support and assistance with this research.

\section{Authors' contributions}

QM provided support and guidance for this study. ZL and YM carried out literature and examination. JC provided the samples. YS was involved in the initial concept of the examination. All authors read and approved the final manuscript.

\section{Funding}

Chinese Ministry of Finance's Special Fund for the Basic Research by Non-Profit Public Research Institutes of Chinese Academy of Cultural Heritage.

\section{Availability of data and materials}

The datasets used during this study are available from the corresponding author on reasonable request.

\section{Competing interests}

The authors declare that they have no competing interests.

\section{Author details}

${ }^{1}$ Institute of Cultural Heritage and History of Science \& Technology, University of Science and Technology Beijing, Beijing 100083, China. ${ }^{2}$ Institute of Cultural Heritage, Shandong University, Jinan 250100, Shandong Province, China. ${ }^{3}$ Henan Provincial Institute of Cultural Heritage and Archaeology, Zhengzhou 450000, Henan Province, China. ${ }^{4}$ Chinese Academy of Cultural Heritage, Beijing 100029, China.

Received: 7 September 2019 Accepted: 12 December 2019 Published online: 03 January 2020

\section{References}

1. Li J. Development of Chinese ancient glaze technology. In: Gan F, editor. Development of Chinese ancient glass. Shanghai: Shanghai Scientific and Technical Publishers; 2005. p. 200-19.

2. Eppler RA. Corrosion of glazes and enamels. In: Clark DE, Zoitos BK, editors. Corrosion of glass, ceramics and ceramic superconductors. New Jersey: Noyes Publications; 1992. p. 372-91.

3. Hench LL. Characterization of glass corrosion and durability. J Non-Cryst Solids. 1975;19:27-39.

4. Doremus RH. Interdiffusion of hydrogen and alkali ions in a glass surface. J Non-Cryst Solids. 1975;19:137-44.

5. Wicks GG, Mosley WC, Whitkop PG, Saturday KA. Durability of simulated wasteglass effects of pressure and formation of surface layers. J NonCryst Solids. 1981;49(1-3):413-28. 
6. Frankel GS, Vienna JD, Lian J, Scully JR, Gin S, Ryan JV, Wang J, Kim SH, Wind I W, Du J. A comparative review of the aqueous corrosion of glasses, crystalline ceramics, and metals. npj. Mater Degrad. 2018;2(1):1-17.

7. Zhang F, Zhang Z. Chinese ancient low temperature color glaze. J Chin Ceram Soc. 1980;8(1):11-21.

8. Li J, Chen X. A study on west Han $\mathrm{PbO} \cdot \mathrm{BaO} \cdot \mathrm{SiO}_{2}$ glass and its corroded layer unearthed at Yang zhou. J Wuhan Univ Technol Mater Sci Ed. 1988;10(2):3-11.

9. Garofano MD, Robador JL, Rodriguez P. Ceramics from the Alcazar Palace in Seville (Spain) dated between the 11th and 15th centuries: compositions, technological features and degradation processes. J Eur Ceram Soc. 2015:35(15):4307-19.

10. Wang J, Li M, Ma Q, Zhang Z, Zhang M, Wang J. Weathering of an octagonal $\mathrm{PbO}-\mathrm{BaO} \cdot \mathrm{SiO}_{2}$ glass stick from the Warring States period. Glass Enamel. 2014;2:6-13.

11. Tiziana L, Lucile G, Aurélie V, Anne C, Claudine L, Dephine N, Eric L. Characterisation of complex alteration layers in medieval glasses. Corros Sci. 2013;72:10-9.

12. Sterpenich J, Libourel G. Using stained glass windows to understand the durability of toxic waste matrices. Chem Geol. 2001:174(1):181-93.

13. Sterpenich J, Libourel G. Water diffusion in silicate glasses under natural weathering conditions: evidence from buried medieval stained glasses. J Non-Cryst Solids. 2006;352(51):5446-51.

14. Verney-Carron A, Gin S, Frugier P, Libourel G. Long-term modeling of alteration-transport coupling: application to a fractured Roman glass. Geochim Cosmochim Acta. 2010;74(8):2291-315

15. Rodrigues A, Fearn S, Palomar T, Vilarigues M. Early stages of surface alteration of soda-rich-silicate glasses in the museum environment. Corros Sci. 2018;143:362-75.

16. Li W, Deng Z, Li J. Cystallization and phase-separation in Chinese Calcia glazes. In: International symposium on ancient ceramics. Shanghai, China; 2006. p.116-25

17. Li J. History of science and technology in China (ceramic volume). 1st ed. Beijing: Science Press; 1998.

18. Li Y, Miao J, Sun X, Feng X, Jia C. Exploring the contributing factors for lineal patterns resembling earthworm mud trails on porcelain from the Juntai kiln. J Gugong Stud. 2013;2:226-33.

19. Zhang $Y$, Ning J, Wang $H$, Sun $X$. Experiments and research on Jun Guan porcelains and glazes in song dynasty of China. B Chin Ceram Soc. 2012;31(6):1580-5.

20. Chen X, Huang R, Chen S, Zhou X, Chen M. The microstructures of the antique Jun(Chun)ware sherds of Henan province. J Chin Ceram Soc. 1981;9(1):245-52

21. Kingery WD, Vandiver PB. Song dynasty Jun (Chün) ware glazes. Am Ceram Soc Bull. 1983;62(11):1269-82.

22. Vandiver PB. Variability of Song Dynasty green glaze technology using microstructure, microcomposition and thermal history to compare
Yaozhou, Jun, Ru, Yue, Longquan, Guan, and Korean Koryo Dynasty materials and practices. In: Shi N, Miao J, editors. Proceedings of International Symposium on Scienc and technology of five great wares of the song dynasty. Beijing: China Science publishing; 2016. p.391-432.

23. Lahlil S, Xu J, Li W. Influence of manufacturing parameters on the crackling process of ancient Chinese glazed ceramics. J Cult Herit. 2015;16(4):401-12.

24. Zhang K. Chinese ancient ceramics science. 1st ed. Shanghai: Shanghai People's Fine Arts Publishing House; 2000.

25. Henan Provincial Institute of Cultural Relics and Archaeology. The Juntai Kilns in Yuzhou. 1st ed. Zhengzhou: Elephant Press; 2008.

26. Wang F, Yang C, Miao J. Jun ware glaze with opalescence, fambe, structural colors and chemical colors. China Ceram. 2015;51(5):1-8.

27. Hou J, Pradell T, Li Y, Miao J. Jun ware glazes: chemistry, nanostructure and optical properties. J Eur Ceram Soc. 2018;38(12):4290-302.

28. Pamela VB. Corrosion and conservation of ancient glass and ceramics. In: Clark DE, Zoitos BK, editors. Corrosion of glass, ceramics and ceramic superconductors. New Jersey: Noyes Publications; 1992. p. 393-432.

29. Wang Q, Li X, Shen X. Crystal structures of silicate minerals. J Nanjing Tech Univ Sci Ed. 2017:39(1):39-45.

30. Schott J, Pokrovsky OS, Spalla O, François D, Gloter A, Mielczarski JA. Formation, growth and transformation of leached layers during silicate minerals dissolution: the example of wollastonite. Geochim Cosmochim Acta. 2012;98(6):259-81.

31. Weissbart EJ, Rimstidt JD. Wollastonite: incongruent dissolution and leached layer formation. Geochim Cosmochim Acta 2000;64(23):4007-16

32. Fröberg L, Kronberg T, TöRnblom S, Hupa L. Chemical durability of glazed surfaces. J Eur Ceram Soc. 2007;27(3):1811-6.

33. FröBerg L, Hupa L, Hupa M. Corrosion of the crystalline phases of matte glazes in aqueous solutions. J Eur Ceram Soc. 2009;29(1):7-14.

34. Hupa L, Bergman R, FröBerg L, Vane-Tempest S, Hupa A, Kronberg T, Pesonen-Leinonen E, SjöBerg A. Chemical resistance and cleanability of glazed surfaces. Surf Sci. 2005;584(1):113-8.

35. Beuvier T, Calvignac B, Bardeau JF, Bulou A, Boury F, Gibaud A. Quantification of the dissolved inorganic carbon species and of the ph of alkaline solutions exposed to $\mathrm{CO}_{2}$ under pressure: a novel approach by Raman scattering. Anal Chem. 2014:86(19):9895-900.

36. Huijgen WJJ, Witkamp GJ, Comans RNJ. Mechanisms of aqueous wollastonite carbonation as a possible $\mathrm{CO}_{2}$ sequestration process. Chem Eng Sci. 2006;61(13):4242-51.

\section{Publisher's Note}

Springer Nature remains neutral with regard to jurisdictional claims in published maps and institutional affiliations.

\section{Submit your manuscript to a SpringerOpen ${ }^{\circ}$ journal and benefit from:}

- Convenient online submission

- Rigorous peer review

- Open access: articles freely available online

- High visibility within the field

Retaining the copyright to your article

Submit your next manuscript at springeropen.com 